\title{
THE RATE OF ABSORPTION OF IODIDE AND GLYCINE FROM THE GASTRO- INTESTINAL TRACT IN NORMAL PERSONS AND IN DISEASE CONDITIONS
}

\author{
By CLARK W. HEATH AND HAROLD W. FULLERTON \\ (From the Thorndike Memorial Laboratory, Second and Fourth Medical Services (Harvard) of the Boston City \\ Hospital, and the Department of Medicine, Harvard Medical School, Boston)
}

(Received for publication March 19, 1935)

Deficiency disease, other than that related to deficient dietary intake or to increased metabolic needs, may result from two kinds of disorder of the gastro-intestinal tract. First, the secretory mechanism, and secondly, the absorptive mechanism may be at fault. The present study is not concerned particularly with the first, an outstanding example of which is diminution or loss of the "intrinsic factor" from the stomach, which is responsible for Addisonian pernicious anemia. The absorptive mechanism may be at fault in a variety of ways, for example, when diarrhea is present, or when there are pathological changes, such as ulcerations of the bowel, infections, stricture or tumor, which may, by mechanisms not well understood, affect motility or produce mucosal changes $(1,2,3)$.

The difference between the dose of iron or liver extract given orally and given parenterally to bring about optimal blood regeneration in certain types of anemia is very great. Absorption of these two substances obviously does not take place with great ease, although, in the case of the antipernicious anemia principle in liver extract, there may be some destruction of the substance in the stomach and bowel. When the mechanism of absorption is disturbed, clinical signs of deficiency of these substances might easily appear without the signs of deficiency of more readily absorbable substances, such as the products of protein, carbohydrate, and fat digestion.

For a number of years it has been felt in this clinic that some method for judging variations in the absorption rate from the gastro-intestinal tract would be of clinical value. This problem is fraught with many difficulties. The method employed in animals of observing the disappearance of a substance in the surgically isolated gut, or the analysis of the contents of the gut removed postmortem, a method used by Cori (4) with success and by many other observers in animal physiology, obviously cannot be used in human beings except under most unusual circumstances.

Study of the length of time between the ingestion of food and its appearance in feces, together with the character of the feces, which Burnett (5) employs as an indication of absorption is of some value but does not yield specific information. The upper small intestine is the organ chiefly concerned with the absorption of necessary elements of the food, and until more information is obtained, it cannot be concluded that the motility of the bowel as a whole or of the colon and rectum in particular, reflects the rate of absorption of materials in the upper small intestine.

Other objections apply to the study of the quantitative chemistry of the food and the feces. The fallacies of such a study appear when it is considered that the gastro-intestinal tract acts as a secretory as well as an absorbing organ. Moreover, food substances, readily detectable in the feces, may be absorbed well when the gastro-intestinal tract is obviously damaged, or they may not be demonstrated, because they are destroyed by enzyme or bacterial action.

These methods of judging the rate of absorption may be classified as direct methods. One must fall back on indirect methods to gain more information in man. The part played by the gastro-intestinal barrier has been frequently taken into account in studies involving the appearance of an ingested substance in the blood stream or in the urine, for example, in the study of glucose tolerance tests. In special circumstances, unusual methods have been employed, examples being the appearance of iodine in the sputum after the ingestion of an iodine salt (6), the transference of weight to distant parts of the body after the drinking of a measured quantity of water (7), the physiological effects of orally adminis- 
tered drugs, and allergic skin reactions to ingested protein (8). Singer and Wechsler (9) state that, in certain types of anemia associated with achlorhydria, no galactose appears in the urine after the administration of 40 grams of galactose, and they emphasize a triad: achylia, severe anemia, and agalactosuria. If true, this extraordinary finding indicates that galactose may be a substance of some general value in the study of the absorptive ability of the gastro-intestinal tract.

Goldschmidt (10) and Magee (11) note that as knowledge in the physiology of the gastrointestinal tract increases, the mechanisms of the absorptive process can be explained more and more by physicochemical laws. The monographs of these authors emphasize the extreme complexity of the absorptive mechanism and the numerous factors which may affect the passage of substances across the intestinal wall. The problem being so complex, it was with great hesitancy that methods were selected for the present investigation. Certain results from the initial approach to the subject seem, however, appropriate for the present report.

In this preliminary work no attempt was made to select for study only cases with undoubted deficiency disease secondary to proved gastro-intestinal pathology. Such dramatic cases, indeed, are not common. Observations were made upon a variety of patients who had some evidence of gastro-intestinal pathology, for example, patients with achlorhydria with or without anemia or upon patients who suffered from some disease process which might affect the absorptive mechanism, such as patients with infectious disease, myxedema, cirrhosis of the liver, scurvy, and nephritis.

\section{METHODS}

A study was made upon the effect of the ingestion by a miscellaneous group of subjects of three different substances: water, potassium iodide and glycine. The first, water ingestion and its rate of excretion in the urine, yielded no information regarding the rate of absorption. The rate of water absorption seemed extremely rapid, but it was felt that the rate of excretion depended upon the function of the kidneys and in particular upon the ability of the tissues to retain water. The latter factor seemed of especial importance when the plasma colloid osmotic pressure was reduced.

Potassium iodide was used in the following manner. The subject, fasting for from fourteen to sixteen hours, swallowed 0.25 gram potassium iodide in $50 \mathrm{cc}$. water. He then rinsed his mouth with and swallowed $200 \mathrm{cc}$. water. Samples of saliva were collected every 2 minutes for $15 \mathrm{~min}$ utes, and then every 5 minutes until an hour after the ingestion of iodide. If iodine had not appeared in the sputum 60 minutes after ingestion, tests were done at hourly intervals. The saliva was tested for iodine as follows: to the samples of about $1 \mathrm{cc}$. each were added 2 drops of 10 per cent ferric chloride and $1 \mathrm{cc}$. starch solution; after twenty minutes the tests were read. The time of first appearance of iodine was the time after ingestion when at least a weakly positive reaction was present, as indicated by a faint blue color. The majority of subjects were required to chew a small amount of paraffin during the test, to ensure an adequate flow of saliva. In general, when the amount of saliva was large the amount of iodine was small, and vice versa. The iodine in the sputum could even be made to disappear, if the flow of saliva was increased greatly by eating. This must have been largely due to dilution of the iodine. The ability of the salivary glands to excrete fluid seemed to bear little relation to their ability to excrete iodine. Since a period of several days elapses before ingested iodine is completely excreted, the tests were repeated on individual subjects at intervals of at least five days.

The tests in which glycine was used were performed upon subjects who had been fasting for 14 to 16 hours. A solution of 25 grams glycine (obtained from Dow Chemical Company) in 400 cc. water was given orally. Twenty-five grams Witte peptone in a similar solution were given to nine patients. Venous blood samples were obtained before administration and at $20,40,60$, 120 , and 180 minutes after administration. The amino-acid nitrogen was determined on the whole blood, in duplicate, by the method of Folin (12).

\section{OBSERVATIONS}

1. The time of the first appearance of iodine in the saliva after the ingestion of potassium iodide. In eight normal individuals the time of the 
first appearance of iodine in the saliva varied between 10 and 15 minutes. The average of all observations on normal subjects was $11.5 \mathrm{~min}$ utes. There was great variation in the length of time during which iodine could still be detected in the saliva. Of 21 patients tested with this in mind, all but two showed no iodine after 20 hours. The average length of time was 13 hours.

Table I summarizes the tests which were made upon patients. In 14 cases of pernicious anemia were: 120,40 and 15 minutes. In two cases of idiopathic hypochromic anemia, while the blood was improving during the administration of iron, a series of tests about ten days apart on the first case showed: $10,8,8,8$, and 6 minutes, respectively; on the second case: $20,15,15,12$ and 12 minutes.

When the potassium iodide was mixed with 25 grams glycine and a large volume of water ( 400 cc.) the time of first appearance was definitely

TABLE I

The time (minutes) of first appearance of iodine in the saliva of patients

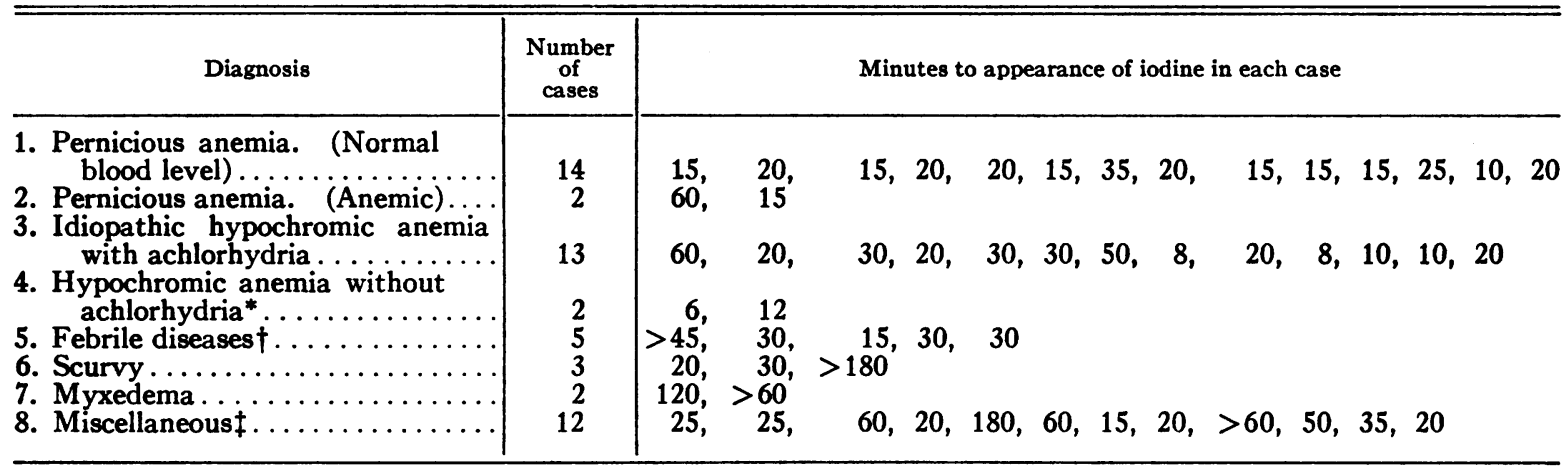

* Hypochromic anemia without achlorhydria: (1) Posterior gastro-enterostomy, bleeding hemorrhoids (the rapid appearance time is very possibly related to a very rapid emptying time of the stomach). (2) Menorrhagia, restricted diet.

† Febrile diseases: (1) Lobar pneumonia in lysis. (2) Pleurisy with effusion. (3 and 4) Chronic arthritis. (5) Lobar pneumonia a few days after crisis.

$\ddagger$ Miscellaneous: (1) Pregnancy, pyelitis. (2) Subtotal gastrectomy two years previously. (3) Myelogenous leukemia, achlorhydria. (4) Thrombocytopenic purpura. (5) Hematemesis from peptic ulcer four days previously. (6 and 7) Alcoholic cirrhosis of liver. (8) Rheumatic heart disease (compensated), asthma. (9) Achlorhydria, no anemia. (10) Chronic nephritis, uremia. (11) Hematemesis ten days previously, ? cause (achlorhydria). (12) Melena, ? cause.

(which were being maintained at a normal blood level by means of injections of liver extract), the appearance time was delayed in 7 . In 13 cases of idiopathic hypochromic anemia, the appearance time was delayed in 9. In a wide variety of clinical conditions the appearance time was delayed.

Tests which were repeated in certain patients, as they were recovering from their disease, nearly always showed a marked diminution of the appearance time of iodine. For example: in a case of lobar pneumonia in lysis the appearance time was more than 45 minutes, and three weeks later it was 10 minutes. A case of scurvy with an initial appearance time of more than 180 minutes, after alleviation of symptoms, showed an appearance time of 20 minutes. In a series of observations upon a case of myxedema during improvement on thyroid medication the appearance times delayed. This variation of the original experiment was repeated often, because it was thought that a combination of the two methods, iodide and glycine, might give results of more value than if the two substances were given at different times. This did not seem to be the case, but a delay of the iodine appearance time was always seen when the iodide was mixed with the glycine solution. This delay may be explained on the basis of the greater dilution of the potassium iodide and upon the presence of glycine inhibiting the absorption of iodine by an antagonistic action (13) or by what Cori terms the " mutual inhibition of absorption" (14). The experiment illustrates the validity of the concept that the appearance time of the iodine in the sputum is influenced at least in part by the rate of absorption in the gastro-intestinal tract. 
Before it can be declared that the appearance time of iodine in the sputum after ingestion is a measure of the rate of absorption from the alimentary tract, it is necessary to take into account a number of factors. The emptying time of the stomach is undoubtedly important. Nevertheless, achlorhydria which was present in most of the patients studied, is usually accompanied by no great change in the emptying time, and the emptying time may be hastened $(15,16)$. A small amount of iodine undoubtedly is absorbed by the mucous membranes of the mouth (17) and of the stomach (18). A slow circulation rate of the blood probably would not delay appreciably the appearance time of iodine. Factors which regulate the level of the iodine of the blood, such as tissue storage or kidney or bowel excretion, may be important. The functional ability of the salivary glands is undoubtedly important.

To assist in ruling out these factors, potassium iodide was given intravenously, and the saliva was tested in the usual way. It was discovered at once, that relatively large amounts of potassium iodide ( 0.075 to 0.1 gram in 5 per cent solution) must be given in order to recover iodine uniformly in the saliva. This fact indicated that the 0.25 gram potassium iodide given by mouth must be rapidly and completely absorbed in normal individuals. The time of appearance of iodine in the saliva after the intravenous injection of 0.075 or 0.1 gram potassium iodide, varied between one and six minutes in sixteen subjects. In three subjects the time of appearance was seven, eight, and ten minutes, respectively. The time of appearance after intravenous administration could not be correlated with the time after oral administration. This fact indicates that variation in the appearance time after oral administration of a uniform dose of potassium iodide is dependent chiefly upon conditions in the gastro-intestinal tract.

To summarize: the appearance time of iodine in the saliva after the ingestion of 0.25 gram potassium iodide is delayed in a wide variety of clinical conditions, including cases of anemia associated with achlorhydria. It is probable that this delay is a rough measure of disturbance of the absorptive ability of the upper small intestine.

2. The amino-acid nitrogen of the blood after the ingestion of glycine and Witte peptone. The fasting whole blood amino-acid nitrogen averaged for all subjects (4 normal individuals and 19 patients) $6.6 \mathrm{mgm}$. per $100 \mathrm{cc}$., the extremes being 5.6 to $7.8 \mathrm{mgm}$. per $100 \mathrm{cc}$. One exception was a value of $9.3 \mathrm{mgm}$. per $100 \mathrm{cc}$. in a case of lobar pneumonia during crisis. These figures correspond closely with those reported by others (19, 20, 21).

Average data for the blood amino-acid nitrogen after the ingestion of glycine or Witte peptone are presented in Figure 1. The rise of aminoacid nitrogen corresponded in general with that reported by Folin and Berglund (19) and Witts (21). The curves for patients resembled those for normal subjects. The amino-acid nitrogen reached the highest level usually in from 60 to 120 minutes after the ingestion of glycine. In some patients, the highest level was not attained until 180 minutes had elapsed, which is very probably abnormal. The most marked example of such a delayed "peak" was in a case of chronic nephritis with uremia. Also, in one case of myxedema, the "peak" was delayed, and in a second case of myxedema the 180-minute value was somewhat elevated. Witts (21) has reported high values of amino-acid nitrogen after glycine ingestion in uremia and myxedema.

On theoretical grounds, a delay in absorption should result in a lower 20-minute amino-acid nitrogen level. The rise of amino-acid nitrogen 20 minutes after the ingestion of glycine was similar in the patients and in the normal subjects, (Figure 1). It was the same in those subjects having a delayed iodine appearance time in the saliva as in those having a normal iodine appearance time. The average curves of the latter two groups are indeed strikingly similar.

The average curve for amino-acid nitrogen of the blood, after the ingestion of 25 grams Witte peptone in nine patients, is similar to the other curves in Figure 1, but shows a somewhat more rapid rise in the first twenty minutes and is of shorter duration. Witte peptone, containing mostly larger molecules than glycine, should theoretically be absorbed more slowly than glycine. The curve (Figure 2), however, might be taken to indicate that Witte peptone is absorbed even more rapidly than glycine. The proper interpretation is, probably, that the factor of absorption in the gastro-intestinal tract plays only a small part in determining the course taken by the amino- 


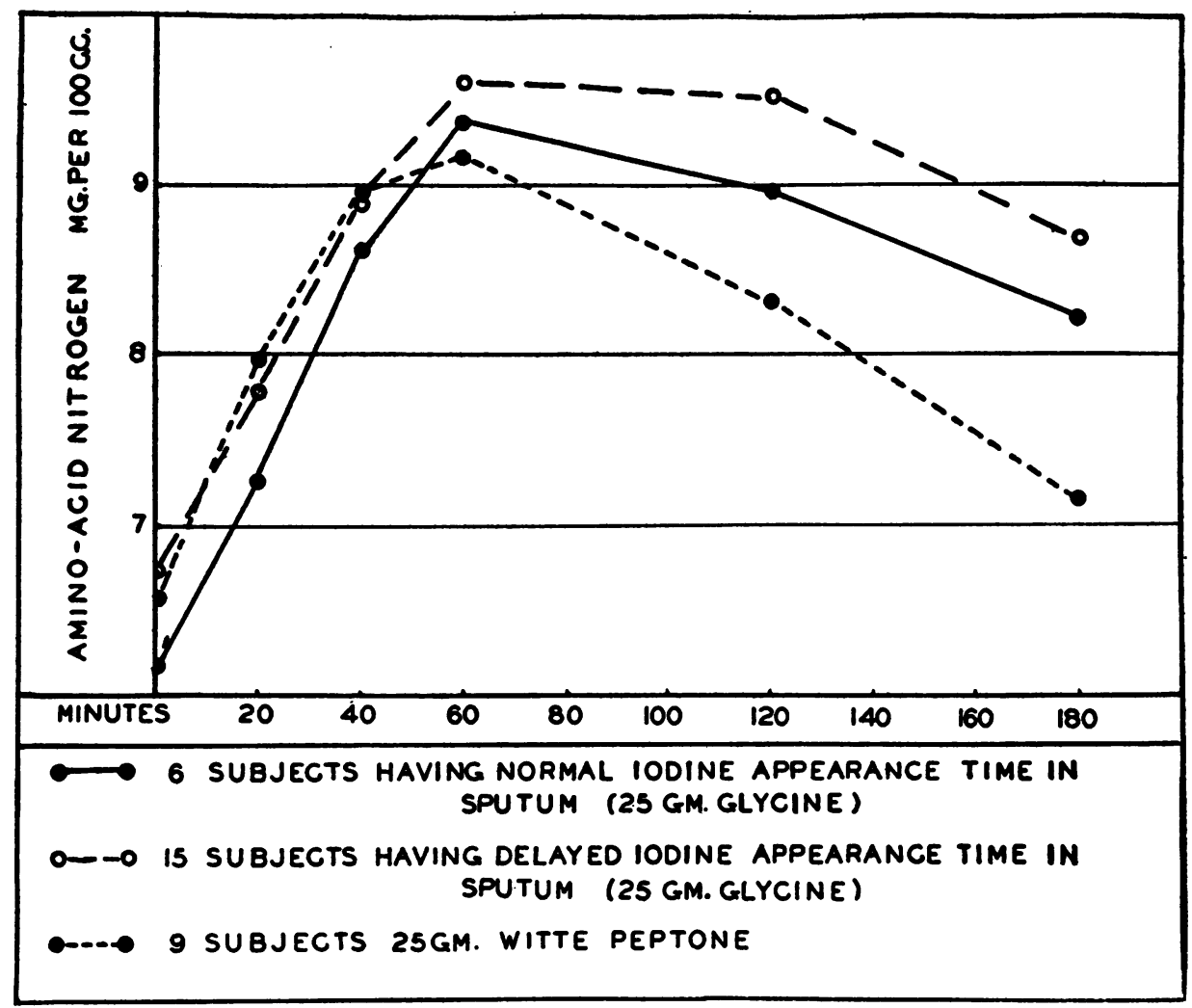

Fig. 1. Average Data of Whole Blood Amino-Actd Nitrogen Following the Ingestion of 25 Grams Glycine, and 25 Grams Witte Peptone.

acid nitrogen of the blood following the ingestion of glycine or of Witte peptone.

In seven patients 4 grams glycine in 10 per cent solution were injected intravenously. The injection was attended by no untoward symptoms. Blood samples were obtained at 4 or $5,20,40,60$ and 80 minutes. In all cases except one, the 4 or 5-minute value ranged between 10.1 and 12.3 mgm. per $100 \mathrm{cc}$. A rapid fall then occurred, and the fasting level was reached in 40 to 80 minutes. The injection of 4 grams glycine should theoretically result in an immediate rise of the blood amino-acid nitrogen to about $22 \mathrm{mgm}$. per $100 \mathrm{cc}$, if the blood volume is $5,000 \mathrm{cc}$. This illustrates how rapidly excess glycine can be removed from the circulating blood. About 75 per cent of the injected 4 grams glycine must be taken up by the tissues or excreted in the urine in the first 4 or 5 minutes.

A marked similarity in the curves obtained after oral and after intravenous administration of glycine was observed in two cases. In one, a case of alcoholic cirrhosis, there was only a moderate rise in both instances; in the other, a case of chronic nephritis with uremia, there was an unusually high rise. The similarity of these curves suggests that the nature of the curve following oral administration of glycine depends more upon the character of the process of removal of glycine from the blood stream, than upon the rate of absorption from the gastro-intestinal tract.

The data presented here suggest that the study of the fate of glycine in the blood stream is without value in interpreting the absorptive capacity of the gastro-intestinal tract. Glycine is absorbed very rapidly, and any difference in the rate of absorption in different patients seems to be offset by the strong tendency of the regulatory mechanism to maintain a normal amino-acid nitrogen content of the blood. This regulatory mechanism is undoubtedly influenced by other factors which cannot be easily controlled. The most important factors are, probably, the previous state of nutrition of the subject, and the needs of the body at the 
time. Martens (22) gives the opinion, that even the permeability of the intestinal mucosa to protein products obeys not only the composition of the intestinal contents, but also the factors of internal metabolism.

In summary, it may be said that the amino-acid nitrogen content of the blood following the ingestion of 25 grams of glycine gives no useful information regarding the rate of absorption from the gastro-intestinal tract.

\section{COMMENT}

It has been pointed out that numerous factors play a rôle in the normal absorptive mechanism. Undoubtedly several of these factors may be altered at one time by disease. It is possible that increased function of one factor may compensate for decreased function of another. It is probable that there occur selective hindrances to the absorption from the gastro-intestinal tract of certain classes of substances, other classes of substances passing the barrier in a normal fashion. The state of affairs being so complex, it would be hazardous to generalize about intestinal permeability from data regarding the absorptive rate of a single substance. The accumulation of much experience is required before definite conclusions regarding absorption can be made upon a given patient.

The study of the appearance time of iodine in the saliva after the ingestion of potassium iodide has shown some strikingly contrasting results in normals and in patients. One is strongly tempted to ascribe these changes to alterations in the absorptive rate of the small bowel, at least in respect to this particular substance. The administration of potassium iodide intravenously whereby the influence of the intestinal barrier is avoided, gives corroborative evidence which favors this conclusion.

It seems unfortunate, at least from the point of view of the study of the absorptive ability of the gastro-intestinal tract, that a substance like glycine which may be detected readily in the blood stream, offers so little information regarding absorption. The internal metabolism of glycine, its storage and disposal, seems to have much more influence upon the level in the blood stream than the rate at which the bowel delivers it to the cir- culation. The same seems to be true of glucose, and Trimble, Carey and Maddock (23) have stated that the concentrations of sugar existing in the venous blood may fail to reflect either the course or the completion of the process of glucose absorption.

Any procedure, however, which gives definite information about the function of absorption of the gastro-intestinal tract would be of considerable clinical value today. It would assist in elucidating problems of minor degrees of malnutrition which so frequently present themselves, and would aid greatly in the treatment of such conditions.

\section{SUMMARY AND CONCLUSIONS}

1. There is much evidence that nutritional deficiency may result from disorders of the gastrointestinal tract which hinder absorption of essential food factors. A suitable test for the functional ability of the absorptive mechanism would be of considerable clinical value.

2. The appearance time of iodine in the saliva, after the ingestion of 0.25 gram potassium iodide, was delayed in a wide variety of clinical conditions, including patients who had achlorhydria or who suffered from some disease process likely to condition a disturbance of the absorptive mechanism. It is believed that this delay is a rough measure of disturbance of the absorptive ability of the upper small intestine.

3. The amino-acid nitrogen content of the blood, following the ingestion of 25 grams glycine, gave no information of value regarding the rate of absorption from the gastro-intestinal tract.

\section{BIBLIOGRAPHY}

1. Keefer, C. S., Some clinical aspects of deficiency disseases. New England J. Med., 1931, 205, 1086.

2. Strauss, M. B., The rôle of the gastro-intestinal tract in conditioning deficiency disease. J. A. M. A., 1934, 103, 1.

3. Mackie, T. T., and Pound, R. E., Changes in the gastro-intestinal tract in deficiency states. J. A. M. A., 1935, 104, 613.

4. Cori, C. F., The fate of sugar in the animal body. I. The rate of absorption of hexoses and pentoses from the intestinal tract. J. Biol. Chem., 1925, 66, 691.

5. Burnett, F. L., The progress of nutrition. New England J. Med., 1934, 211, 68. 
6. Thienes, C. H., and Hockett, A. J., Decreased absorption from the alimentary tract following injection of posterior pituitary extract. J. Lab. and Clin. Med., 1931, 16, 843.

7. Smirk, F. H., The rate of water absorption in man and the relationship of the water load in tissues to diuresis. J. Physiol., 1933, 78, 113.

8. Prausnitz, C., and Küstner, H., Studien über die Ueberempfindlichkeit. Zentralbl. f. Bakt., 1921, 86, 160.

9. Singer, K., and Wechsler, L., Klinische Bedeutung und Entstehungsmechanismus des Symptoms: Agalaktosurie. Wien. klin. Wchnschr., 1934, 47, 77.

10. Goldschmidt, S., On the mechanism of absorption from the intestine. Physiol. Rev., 1921, 1, 421.

11. Magee, $H$. E., The rôle of the small intestine in nutrition. Physiol. Rev., 1930, 10, 473.

12. Folin, O., A system of blood analysis. Supplement III. A new colorimetric method for the determination of the amino-acid nitrogen in blood. J. Biol. Chem., 1922, 51, 377.

13. Loeb, J., The mechanism of the diffusion of electrolytes through the membranes of living cells. I. The necessity of a general salt effect upon the membrane as a prerequisite for this diffusion. J. Biol. Chem., 1916, 27, 339. II. The diffusion of $\mathrm{KCl}$ out of the egg of fundulus and the relative efficiency of different ions for the salt effect. Ibid., 1916, 27, 353. III. The analogy of the mechanism of the diffusion for acids and potassium salts. Ibid., 1916, 27, 363. IV. The ratio of the concentration required for the accelerating and antagonistic action upon the diffusion of potassium salts. Ibid., 1916, 28, 175.
14. Cori, C. F., The absorption of glycine and d, 1alanine. Proc. Soc. Exper. Biol. and Med., 1926, 24, 125.

15. Wilkinson, J. F., The gastric secretion in pernicious anaemia. Quart. J. Med., 1932, n.s. 1, 361.

16. Hartfall, S. J., and Witts, L. J., Gastric secretion in simple achlorhydric and allied anaemias. Guy's Hosp. Rep., 1933, 83, 3.

17. Schuntermann, C. E., Untersuchungen über das Resorptionsvermögen der Mundhöhlenschleimhaut. Ztschr. f. d. ges. exper. Med., 1933, 87, 247.

18. Cohn, B. N. E., Absorption of compound solution of iodine from the gastro-intestinal tract, with special reference to the absorption of free iodine. Arch. Int. Med., 1932, 49, 950.

19. Folin, O., and Berglund, H., The retention and distribution of amino-acids with especial reference to the urea formation. J. Biol. Chem., 1922, 51, 395.

20. Greene, C. H., Sandiford, K., and Ross, H., The amino-acid content of the blood in normal and pathological conditions. J. Biol. Chem., 1924, 58, 845.

21. Witts, L., Observations on the metabolism of aminoacids in health and disease. Quart. J. Med., 1929, 22, 477.

22. Martens, R., Les principaux facteurs de la régulation de l'Aminoacidémie et de la Peptidémie-Etude Physio-Pathologique. Arch. internat. de méd. expér., 1933, 8, 361.

23. Trimble, H. C., Carey, B. W., Jr., and Maddock, S. $\mathrm{J}$., The rate of absorption of glucose from the gastro-intestinal tract of the dog. J. Biol. Chem., 1933, 100, 125. 